\title{
Variability in, and factors associated with, sizing of polyps by endoscopists at a large community practice
}

\section{(ㄷ)(1) $\odot \odot$}

Authors

Saleh Elwir ${ }^{1}$, Aasma Shaukat ${ }^{1,2}$, Michael Shaw ${ }^{1}$, John Hughes ${ }^{3}$, Joshua Colton ${ }^{4}$

Institutions

1 Division of Gastroenterology, Hepatology and Nutrition, University of Minnesota, Minneapolis, Minnesota, USA

2 Division of Gastroenterology and Hepatology, Minneapolis VA Medical Center, Minneapolis, Minnesota, USA

3 Department of Biostatistics and Informatics, Colorado School of Public Health, University of Colorado, Denver, Colorado, USA

4 Minnesota Gastroenterology, PA, St. Paul, Minnesota, USA

submitted 25.10.2016

accepted after revision 2.5.2017

\author{
Bibliography \\ DOI https://doi.org/10.1055/s-0043-112246 | \\ Endoscopy International Open 2017; 05: E742-E745 \\ (c) Georg Thieme Verlag KG Stuttgart · New York \\ ISSN 2364-3722
}

Corresponding author

Saleh Elwir, MD, Division of Gastroenterology, Hepatology and Nutrition, University of Minnesota, 406 Harvard St. SE, MMC 36, Minneapolis, MN 55455, USA

Fax: +1-612-625-5620

elwir001@umn.edu

\section{ABSTRACT}

Background and aims Accurate sizing of polyps at time of colonoscopy is critical for determining surveillance intervals. Endoscopists routinely over- or underestimate the size of polyps at colonoscopy. We evaluated the variability in sizing of polyps among multiple endoscopists, and the effect of patient and physician related factors on polyp size estimation in a large community-based practice.

Methods Adult patients who underwent a colonoscopy with polypectomy at five endoscopy centers in Minneapolis/St. Paul by one of 52 endoscopists in 2013 were included in this study. Association of patient, physician, and procedure related factors on polyp sizing was assessed.

Results In the study time frame, 38624 colonoscopies were performed at five ambulatory endoscopy centers. Of these, 16336 had one or more polyp removed with size information available, and were included in this analysis. There was significant inter-physician variation for estimating polyp sizes larger than $5 \mathrm{~mm}$ (intraclass correlation coefficient [ICC] 0.13). Older patient age (OR 1.08, 95\%Cl $1.06-1.11$ ), and male physician gender (OR $1.92,95 \% \mathrm{Cl}$ $1.26-2.94)$ were associated with increased odds of physicians sizing polyps as larger in size. Surveillance procedures had a higher odds of larger polyp sizing compared to screening (OR $0.91,95 \% \mathrm{Cl} 0.86-0.97)$ and diagnostic procedures (OR 0.86, $95 \% \mathrm{Cl} 0.78-0.94$ ).

Conclusion In a large community setting, variation of polyp sizing estimates exists between physicians. Male physicians were more likely to size polyps as larger in size. Older patients and patients undergoing surveillance procedures were more likely to have polyps that were sized as larger in size.

\section{Introduction}

Colonoscopy is an established method in colorectal cancer screening [1,2]. Polyp size, number, and histology are used in the current guidelines to determine timing of surveillance colonoscopy [2]. Several tools have been suggested to aid in accurate estimation of polyp size, including use of open biopsy forceps as a reference and use of certain calibers [3-7]; however, most endoscopists tend to use visual estimation in predicting polyp size. Evidence suggests that endoscopists routinely overor underestimate the size of polyps at colonoscopy [8-10].

In this study, we evaluated variability in sizing of polyps between multiple endoscopists, and the effect of patient and physician related factors on polyp size estimation in a large community-based practice. 
- Table 1 Patient and procedure related characteristics.

\begin{tabular}{|l|c|}
\hline & $\mathbf{n}(\%)$ \\
\hline Number of patients & $16336(100 \%)$ \\
\hline Male patients & $8658(53 \%)$ \\
\hline Patient age (mean) & $61.5(20-96)$ \\
\hline Indication & \\
\hline - Diagnostic colonoscopy & $2123(13 \%)$ \\
\hline - Screening colonoscopy & $8658(53 \%)$ \\
\hline - Surveillance colonoscopy & $5555(34 \%)$ \\
\hline Total polyp number & 40652 \\
\hline Polyps 1 - 4 mm (\% total) & $27316(67 \%)$ \\
\hline Polyps $>5$ mm (\% total) & $13336(33 \%)$ \\
\hline Polyps $\geq 10$ mm (\% total) & $1505(3.7 \%)$ \\
\hline
\end{tabular}

\section{Methods}

We collected information on all colonoscopy examinations performed within five ambulatory endoscopy centers (AECS) in a large community-based practice in the Twin Cities of Minnesota (Minnesota Gastroenterology P.A.) during a 1-year period from January 2013 to December 2013. Patients were excluded if no polyps were found during the examination, the exact size of polyps was not documented in the endoscopy report, multiple polyps were grouped together in a size range rather than individually reported, or when information was missing. Information including patient demographics, endoscopic findings, and pathology results is contained within a single database of the electronic medical records (NextGen Healthcare, Atlanta, GA, USA). Patient demographics, indication for colonoscopy, number, size, and location of polyps were collected. Physician age, sex, adenoma detection rate (ADR), and years in practice were also collected. Size of polyps used in the analysis was the size estimated by the endoscopist at the time of the procedure which was based on visual estimation. Association of these factors on polyp sizing was assessed by a logistic regression model. We dichotomized the polyp sizes using a threshold of $5 \mathrm{~mm}$. A size of $5 \mathrm{~mm}$ was used as a cutoff with polyps analyzed in a $1-4 \mathrm{~mm}$ group, and a $5 \mathrm{~mm}$ or larger group. The $5 \mathrm{~mm}$ cutoff was chosen given its significance as, below this threshold, a "resect and discard" approach can be applied. The number of advanced polyps (larger than $10 \mathrm{~mm}$ ) in the final data set was small (3.7\% of total polyps), precluding meaningful analyses. We applied a mixed effects logistic regression model to the resulting binary data. Specifically, we included a random intercept for each physician to accommodate withinphysician dependence, and we included as covariates polyp location, patient age, patient sex, procedure type (screening, surveillance or diagnostic), physician sex, time elapsed since the physician completed medical school, ADR female, ADR male, and total number of colonoscopies. We carried out all analyses using the Ime4 package for R (R Core Team (2015).
- Table 2 Patient and procedure related characteristics in procedures performed by male and female physicians.

\begin{tabular}{|c|c|c|}
\hline Indication & $\begin{array}{l}\text { Female physician } \\
(n=13)\end{array}$ & $\begin{array}{l}\text { Male physician } \\
(n=39)\end{array}$ \\
\hline Male patients (\%) & $1416(36 \%)$ & $7276(59 \%)$ \\
\hline $\begin{array}{l}\text { - Diagnostic (n) } \\
\text { Polyps >5 mm }\end{array}$ & $\begin{array}{l}11 \%(156) \\
18 \%(28)\end{array}$ & $\begin{array}{l}10 \%(728) \\
39 \%(284)\end{array}$ \\
\hline $\begin{array}{l}\text { - Screening (n) } \\
\text { Polyps >5 mm }\end{array}$ & $\begin{array}{l}60 \%(849) \\
20 \%(170)\end{array}$ & $\begin{array}{l}52 \%(3783) \\
35 \%(1324)\end{array}$ \\
\hline $\begin{array}{l}\text { - Surveillance (n) } \\
\text { Polyps >5 mm }\end{array}$ & $\begin{array}{l}29 \%(411) \\
18 \%(74)\end{array}$ & $\begin{array}{l}38 \%(2765) \\
35 \%(968)\end{array}$ \\
\hline Female patients (\%) & $2568(64 \%)$ & $5048(41 \%)$ \\
\hline $\begin{array}{l}\text { - Diagnostic (n) } \\
\text { Polyps }>5 \mathrm{~mm}\end{array}$ & $\begin{array}{l}13 \%(337) \\
26 \%(88)\end{array}$ & $\begin{array}{l}17 \%(858) \\
34 \%(292)\end{array}$ \\
\hline $\begin{array}{l}\text { - Screening (n) } \\
\text { Polyps }>5 \mathrm{~mm}\end{array}$ & $\begin{array}{l}60 \%(1530) \\
21 \%(321)\end{array}$ & $\begin{array}{l}51 \%(2575) \\
37 \%(952)\end{array}$ \\
\hline $\begin{array}{l}\text { - Surveillance (n) } \\
\text { Polyps >5 mm }\end{array}$ & $\begin{array}{l}27 \%(701) \\
21 \%(147)\end{array}$ & $\begin{array}{l}32 \%(1615) \\
35 \%(565)\end{array}$ \\
\hline
\end{tabular}

R Foundation for Statistical Computing, Vienna, Austria. URL https://www.R-project.org; date accessed 3 May 2016) [11].

\section{Results}

In the study time frame, 38624 colonoscopies were performed at five ambulatory endoscopy centers. In total, 22017 (57\%) colonoscopies had polyps detected and of these, 16336 (75\%) were included in this analysis; 5681 records were excluded when the exact size of polyps was not provided, multiple polyps were grouped together or when information was missing.

In total, $53 \%$ of the patients were men with a mean age of 61.5 (range 20 - 96 years); $13 \%$ of the procedures were diagnostic while $53 \%$ were for screening and $34 \%$ for surveillance purposes ( $\vee$ Table 1 ). Colonoscopies were performed by one of 52 physicians ( $75 \%$ males, mean age 51.4 years). Physicians had been in practice for a mean of 18.1 years (range 2-41 years) and had performed an average of 716 colonoscopies per year (range 109-1065) with a mean adenoma detection rate (ADR) of $45.6 \%$ for male patients and $32.3 \%$ for female patients.

Female physicians performed the majority of the colonoscopies $(64 \%)$ on female patients with screening colonoscopies making up $59 \%$ of the total procedures, surveillance colonoscopies in $28 \%$, and diagnostic colonoscopies in $13 \%$. Male physicians had a majority male patient population (59\%) with $51 \%$ being screening, $35 \%$ surveillance, and $14 \%$ diagnostic colonoscopies ( $\triangleright$ Table 2 ).

There was significant inter-physician variation for estimating polyp sizes as larger than $5 \mathrm{~mm}$ with an inter-physician correlation coefficient of $0.13(P<0.001)$ suggesting large inter-physician variability ( $>$ Fig. 1). Male physicians had higher odds of sizing polyps as larger, regardless of indication (36\% of polyps sized $>5 \mathrm{~mm}$ by male physicians compared to $24 \%$ by female physicians; $P<0.001)$. Years in practice, ADR or annual colonos- 


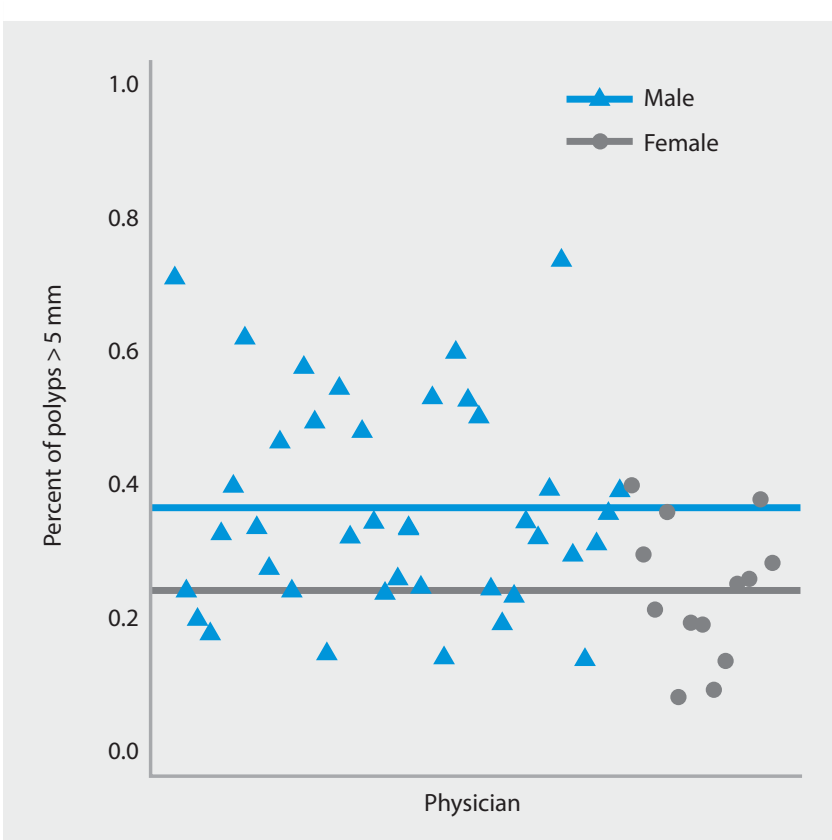

- Fig. 1 Percentage of polyps sized as larger than $5 \mathrm{~mm}$ by each physician. Means for male and female physicians represented by horizontal lines.

copy volume were not associated with variability in polyp sizing. While female patients were more likely to see a female physician, stratified by patient gender and age, the difference in polyp sizing for male and female physicians persisted as male physicians found larger polyps, on average, than did female physicians for male patients $(P<0.001)$. Male physicians found larger polyps, on average, than did female physicians for female patients $(P<0.001)$.

In a logistic regression model, older patient age, male physician gender, and procedure indication were associated with increased odds of physicians sizing polyps as larger in size ( $\triangleright \mathbf{T a -}$ ble3). Surveillance procedures had a higher odds of larger polyp sizing compared to screening (OR for polyps $>5 \mathrm{~mm}$ $0.91,95 \% \mathrm{Cl} 0.86-0.97)$ and also compared to diagnostic procedures (OR $0.86,95 \% \mathrm{Cl} 0.78-0.94)$.

\section{Discussion}

Most endoscopists rely on subjective visual estimates when determining polyp size during colonoscopy. Studies have shown that this will result in endoscopists overestimating $[8,12,13]$ or underestimating polyp size $[9,10,14]$; however, to our knowledge, no studies have specifically evaluated the variability in polyp sizing among physicians that are performing colonoscopy on similar patients. Furthermore, factors that may explain the variation in polyp sizing have not been reported. We observed large inter-physician variation in sizing of polyps in a large community practice. We also observed that male physicians were more likely to size polyps as larger compared to female physicians, and this difference was seen regardless of indication. While female patients were more likely to see a female physician, stratified by patient gender and age, the difference
Table 3 Estimated conditional odds ratios and 95\% confidence intervals.

\begin{tabular}{|l|l|l|}
\hline Variable & OR & $95 \% \mathrm{Cl}$ \\
\hline Patient age & 1.08 & $1.06-1.11$ \\
\hline Patient gender (male) & 1.01 & $0.96-1.06$ \\
\hline Indication (surveillance) & 0.86 & $0.79-0.93$ \\
\hline Indication (screening) & 0.94 & $0.87-1.01$ \\
\hline Physician gender (male) & 1.92 & $1.26-2.94$ \\
\hline Years since physician graduation & 0.74 & $0.22-2.50$ \\
\hline ADR female & 0.81 & $0.61-1.10$ \\
\hline ADR male & 1.24 & $0.95-1.63$ \\
\hline Number of colonoscopies per year & 1.14 & $0.99-1.32$ \\
\hline ADR, adenoma detection rate. & & \\
\hline
\end{tabular}

in polyp sizing for male and female physicians persisted indicating that the variability was from factors other than patient characteristics. The reasons for this observation are unclear but merit further study.

For patient factors, older patient age and surveillance exams were associated with increased odds of sizing polyps as large. These findings are consistent with earlier reports. Lieberman and colleagues [15] have reported that the risk of large polyps (defined as larger than $9 \mathrm{~mm}$ ) progressively increases with advancing age beyond age 75 years in both male and female patients. The same study showed that female patients had a lower prevalence of polyps larger than $9 \mathrm{~mm}$ [15]. Other studies have shown an increase in ADR with increasing patient age [15-17] and in male as compared to female patients [16-19]. In a population-based study from the New Hampshire Colonoscopy Registry, the ADR was significantly higher in surveillance colonoscopies (37\%) than screening colonoscopies (25\%; $P<$ 0.001 ) which is similar to the results of this study [13].

Our study has several clinical implications. It underscores the importance of studying inter-physician variability in sizing of polyps, particularly as this determines surveillance intervals. As polyp size is one of the factors that determine the timing of the next surveillance colonoscopy [2], mis-sizing of polyps can change the timing of surveillance colonoscopy [12].

Another area where polyp size is important is when the "resect and discard" approach is applied. In this strategy, diminutive polyps (polyps less than $5 \mathrm{~mm}$ ) are removed and discarded without pathological examination [20]. Rex and colleagues have reported a low chance of advanced histology in diminutive polyps [21]. In the DISCARD (Detect, InSpect, ChAracterize, Resect, and Discard) trial, optical assessment of the polyps before resection had an overall accuracy of $0.93(0.89-0.96)$ for polyp characterization [22]. In a simulation model, this strategy resulted in a substantial economic benefit without an impact on efficacy [23].

The strengths of our study include a community-based practice, multiple sites, and the large number of physicians per- 
forming the examinations. Limitations include the absence of a gold standard measurement of polyps to compare estimated polyp size to actual polyp size. Despite that, one would assume that with a homogenous patient population, the average size of polyps should be similar across different physicians and that inter-physician variability should not exist.

To our knowledge, our study is the first to report that factors such as male physician, older patients, and indication of surveillance are associated with overestimation of polyp size. The reasons for these findings are unclear, and need to be confirmed by other studies. Possible explanations are that older age and surveillance are risk factors for larger and advanced polyps, and this may be a subconscious bias for the endoscopists. The difference in polyp sizing by male versus female physicians also needs to be confirmed by other studies. Possible explanations include differences in training, differences in practice patterns, and a smaller volume of colonoscopies with larger polyps for female physicians.

It will be important to use the information from this study to develop strategies and tools to address the modifiable factors that contribute to inter-physician variability and which should result in accurate and reliable polyp sizing.

\section{Competing interests}

Dr Colton is a stock holder in Genii Corporation.

\section{References}

[1] Shaukat A, Mongin S], Geisser MS et al. Long-term mortality after screening for colorectal cancer. NEJM 2013; 369: 1106 - 1114

[2] Lieberman DA, Rex DK, Winawer S] et al. Guidelines for colonoscopy surveillance after screening and polypectomy: a consensus update by the US Multi-Society Task Force on Colorectal Cancer. Gastroenterology 2012; 143: $844-857$

[3] Gopalswamy N, Shenoy VN, Choudhry U et al. Is in vivo measurement of size of polyps during colonoscopy accurate? Gastrointest Endosc 1997; 46: 497-502

[4] Jin HY, Leng Q. Use of disposable graduated biopsy forceps improves accuracy of polyp size measurements during endoscopy. World J Gastroenterol 2015; 21: 623-628

[5] Leng Q, Jin HY. Measurement system that improves the accuracy of polyp size determined at colonoscopy. World J Gastroenterol 2015; 21: $2178-2182$

[6] Rex DK, Rabinovitz R. Variable interpretation of polyp size by using open forceps by experienced colonoscopists. Gastrointest Endosc 2014; 79: $402-407$

[7] Winawer S], Zauber AG, O'Brien M] et al. Randomized comparison of surveillance intervals after colonoscopic removal of newly diagnosed adenomatous polyps. The National Polyp Study Workgroup. NEJM 1993; 328: $901-906$

[8] Chaptini L, Chaaya A, Depalma F et al. Variation in polyp size estimation among endoscopists and impact on surveillance intervals. Gastrointest Endosc 2014; 80: 652 - 659

[9] Margulies C, Krevsky B, Catalano MF. How accurate are endoscopic estimates of size? Gastrointest Endosc 1994; 40: 174-177

[10] Moug S], Vernall N, Saldanha J et al. Endoscopists' estimation of size should not determine surveillance of colonic polyps. Colorectal Dis 2010; 12: 646-650

[11] Bates D, Maechler M, Bolker B et al. Fitting linear mixed-effects models using Ime4. J Stat Softw 2015; 67: 1-48

[12] Eichenseer PJ, Dhanekula R, Jakate $S$ et al. Endoscopic mis-sizing of polyps changes colorectal cancer surveillance recommendations. Dis Colon Rectum 2013; 56: 315-321

[13] Anderson BW, Smyrk TC, Anderson KS et al. Endoscopic overestimation of colorectal polyp size. Gastrointest Endosc 2016; 83: 201 - 208

[14] Fennerty MB, Davidson J, Emerson SS et al. Are endoscopic measurements of colonic polyps reliable? Am J Gastroenterol 1993; 88: 496 500

[15] Lieberman DA, Williams JL, Holub JL et al. Race, ethnicity, and sex affect risk for polyps $>9 \mathrm{~mm}$ in average-risk individuals. Gastroenterology 2014; 147: 351 - 358 ; quiz e14-e15

[16] Klein JL, Okcu M, Preisegger KH et al. Distribution, size and shape of colorectal adenomas as determined by a colonoscopist with a high lesion detection rate: Influence of age, sex and colonoscopy indication. United Eur Gastroenterol J 2016; 4: 438-448

[17] Corley DA, Jensen CD, Marks AR et al. Variation of adenoma prevalence by age, sex, race, and colon location in a large population: implications for screening and quality programs. Clin Gastroenterol Hepatol 2013; 11: $172-180$

[18] Ferlitsch M, Reinhart K, Pramhas S et al. Sex-specific prevalence of adenomas, advanced adenomas, and colorectal cancer in individuals undergoing screening colonoscopy. JAMA 2011; 306: 1352-1358

[19] Sanaka MR, Gohel T, Podugu A et al. Adenoma and sessile serrated polyp detection rates: variation by patient sex and colonic segment but not specialty of the endoscopist. Dis Colon Rectum 2014; 57 : $1113-1119$

[20] Abu Dayyeh BK, Thosani N et al. ASGE Technology Committee. ASGE Technology Committee systematic review and meta-analysis assessing the ASGE PIVI thresholds for adopting real-time endoscopic assessment of the histology of diminutive colorectal polyps. Gastrointest Endosc 2015; 81: 502.e1 - 502.e16

[21] Rex DK, Overhiser AJ, Chen SC et al. Estimation of impact of American College of Radiology recommendations on CT colonography reporting for resection of high-risk adenoma findings. Am J Gastroenterol 2009; 104: 149-153

[22] Ignjatovic A, East JE, Suzuki $\mathrm{N}$ et al. Optical diagnosis of small colorectal polyps at routine colonoscopy (Detect InSpect ChAracterise Resect and Discard; DISCARD trial): a prospective cohort study. Lancet Oncol 2009; 10: 1171 - 1178

[23] Hassan C, Pickhardt PJ, Rex DK. A resect and discard strategy would improve cost-effectiveness of colorectal cancer screening. Clin Gastroenterol Hepatol 2010; 8: 865-869, 869.e1-869.e3 